\title{
Selective ex-vivo photothermal ablation of human pancreatic cancer with albumin functionalized multiwalled carbon nanotubes
}

This article was published in the following Dove Press journal:

International Journal of Nanomedicine

28 April 201 I

Number of times this article has been viewed

\author{
Lucian Mocan' \\ Flaviu A Tabaran ${ }^{2}$ \\ Teodora Mocan' \\ Constantin Bele ${ }^{3}$ \\ Anamaria loana Orza' \\ Ciprian Lucan ${ }^{4}$ \\ Rares Stiufiuc' \\ loana Manaila' \\ Ferencz Iulia' \\ lancu Dana' \\ Florin Zaharie' \\ Gelu Osian' \\ Liviu Vlad' \\ Cornel lancu' \\ 'Department of Nanomedicine, "Iuliu \\ Hatieganu" University of Medicine \\ and Pharmacy, Cluj-Napoca, Romania; \\ ${ }^{2}$ Department of Pathology, University \\ of Agricultural Sciences and Veterinary \\ Medicine, Cluj-Napoca, Romania; \\ ${ }^{3}$ Department of Biochemistry, \\ University of Agricultural Sciences \\ and Veterinary Medicine, Cluj-Napoca, \\ Romania; ${ }^{4}$ Clinical Institute of Urology \\ and Renal Transplantation, \\ Cluj-Napoca, Romania
}

Correspondence: Cornel lancu 3rd Surgery Clinic, Department of Nanomedicine, "Iuliu Hatieganu" University of Medicine and Pharmacy, 19-2| Croitorilor Street,

Cluj-Napoca, Romania

$\mathrm{Tel}+40264439696$

Fax +40 264439696

Email cornel.iancu@umfcluj.ro

\begin{abstract}
The process of laser-mediated ablation of cancer cells marked with biofunctionalized carbon nanotubes is frequently called "nanophotothermolysis". We herein present a method of selective nanophotothermolisys of pancreatic cancer (PC) using multiwalled carbon nanotubes (MWCNTs) functionalized with human serum albumin (HSA). With the purpose of testing the therapeutic value of these nanobioconjugates, we have developed an ex-vivo experimental platform. Surgically resected specimens from patients with PC were preserved in a cold medium and kept alive via intra-arterial perfusion. Additionally, the HSA-MWCNTs have been intraarterially administered in the greater pancreatic artery under ultrasound guidance. Confocal and transmission electron microscopy combined with immunohistochemical staining have confirmed the selective accumulation of HSA-MWCNTs inside the human PC tissue. The external laser irradiation of the specimen has significantly produced extensive necrosis of the malign tissue after the intra-arterial administration of HSA-MWCNTs, without any harmful effects on the surrounding healthy parenchyma. We have obtained a selective photothermal ablation of the malign tissue based on the selective internalization of MWCNTs with HSA cargo inside the pancreatic adenocarcinoma after the ex-vivo intra-arterial perfusion.
\end{abstract}

Keywords: noncovalent functionalization, irradiation, tumor, malignant, MWCNTs

\section{Introduction}

Pancreatic cancer (PC) is the fourth leading cause of cancer death in the United States, with an overall 5-year survival rate of less than $5 \% .{ }^{1}$ Only the surgical resection of the primary tumor provides clinical benefit and improvement in survival. However, this is rarely achieved in practice because, at the time of diagnosis, most PC patients have advanced-stage disease and experience various symptoms such as severe pain, jaundice, and weight loss. PC is also one of the most intrinsically drug-resistant of all tumors and the lack of effective cytostatics contributes to the increased mortality rates. ${ }^{2}$

The development of targeted therapy represents an exciting and new approach to PC treatment. Conceptually speaking, a targeted drug represents a responsive molecule attached to a delivery carrier with affinity for specific surface receptor proteins located in cell membranes. ${ }^{3}$ Being endowed with target specificity, the carrier has the ability to concentrate only on the desired biological area. The use of these biological carriers for the development of specific and sensitive site-targeted bionanosystems makes the selective internalization of molecules with photothermal properties in cancer cells possible. This internalization process is not possible under normal conditions. ${ }^{4}$

Studies suggest that nanotechnologies could play a major role in the development of new anticancer therapies. ${ }^{5}$ Thermal approach of nanoparticles, nanoemulsion, 
pH-responsive nanoparticles, nanoparticles used in combination with radiation and nanovectors for drug delivery are the most explored nanoparticle-based cancer treatment methods. $^{6}$

Nanotechnology has already brought to light promising results in PC research and treatment. Gold nanoparticles were used to achieve a radiofrequency-mediated necrosis of PC cells. ${ }^{7}$ F19 monoclonal antibodies conjugated to gold nanoparticles have demonstrated efficiency in targeting the pancreatic carcinoma tissue. ${ }^{8}$ Our previous work shows that carbon nanotubes (CNTs) alter the in-vitro molecular mechanisms of chemoresistance of PC cells. ${ }^{9}$

Highly proliferative tumor cells were shown to present intracytoplasmic albumin deposits. ${ }^{10}$ Another study confirmed that malign tumors are able to internalize albumin through endocytosis which is further processed in lysosomes. ${ }^{11}$ The resulting amino acids are further used for the synthesis of various substrates needed for tumor growth. ${ }^{12,13}$ Based on these properties, the anticancer effect of albumin has been intensively studied. For instance, a combination of cytostatic drug and albumin called Trexall ${ }^{\mathrm{TM}}$ is currently prescribed for the treatment of metastatic PC in humans. ${ }^{14}$

The research mechanisms involving the selective tumor targeting of biofunctionalized CNTs are currently being intensely explored due to the impressive ability of CNTs to convert near-infrared (NIR) laser radiation into heat. This intrinsic property provides an opportunity to develop a new generation of immunoconjugates for cancer photo-therapy with high performance and efficacy in the selective thermal ablation of malignant cells. ${ }^{15}$ Although the idea and the principles of such bioconjugation hold a tremendous potential for the future, $100 \%$ selective internalization of nanobioconjugates in the cancer cells still remains problematic. ${ }^{16}$ While progress has been made regarding biofunctionalization of CNTs using various biological molecules such as DNA, antibodies, folates, and growth factors, ${ }^{17-19}$ there is a significant lack of knowledge on how to obtain selectivity of these compounds for a single type of cancer cell. This is due to the simultaneous presence of the receptors used for the specific binding of the targeting molecules to the membranes of the noncancerous cells too, although in smaller amount compared with the cancer cells. $^{20}$

Animal models of human cancer have been widely used for testing experimental cancer nanotherapies. ${ }^{21}$ Despite their popularity, these models exhibit major flaws because human tumor cells undergo kinetic changes after transplantation, and passage in the nude mice and the majority of the xenografted human tumors do not maintain the morphological and biochemical characteristics of the original tumors. ${ }^{22}$ Therefore, this methodological gap between testing new cancer therapies in humans, on the one hand, and animal models, on the other hand, can be avoided using ex-vivo perfusion techniques of surgically resected organs under cold storage. ${ }^{23}$

Considering these data and the important role of albumin in tumor metabolism, we have used human albumin bound to multiwalled CNTs (MWCNTs) for the selective targeting of PC cells. Since ethical limitations made the selectivity and therapeutic potential of these nanocompounds in patients impossible to test, we have designed an original model of living PC. We used ex-vivo-perfused pancreatic specimens that have been surgically removed from patients with ductal adenocarcinoma. On this model, the intra-arterial administration of albumin conjugated with MWCNTs specifically induced the release of this nanobioconjugate inside the malign tissue via the "capillary bed". We present herein data suggesting that extensive and selective tumoral necrosis was obtained when the living pancreas underwent laser irradiation after the administration of human serum albumin (HSA)-MWCNTs via the greater pancreatic artery.

\section{Materials and methods Antibodies and reagents}

For the experiments involving the noncovalent functionalization of CNTs, MWCNTs ( $>98 \%$ carbon basis, optical density $[\mathrm{OD}] \times$ internal diameter $[\mathrm{ID}] \times \mathrm{L}$ $10-15 \mathrm{~nm} \times 2-6 \mathrm{~nm} \times 0.1-10.0 \mathrm{im}$; product number: 677248), HSA, and Sephacryl ${ }^{\mathrm{TM}} 100-\mathrm{HR}$ were purchased from Sigma Chemical Co (Deisenhofen, Germany), and all the other chemicals were purchased from Merck (Darmstadt, Germany). For the experiments involving the biofunctionalization of CNTs, pancreatic prelevation, and preservation we used Custodiol and Ringer solutions purchased from Essential Pharmaceutics (Newtown, PA). For experiments involving tissue viability, transferase dUTP nick end labeling (TUNEL) TMR Red assay was purchased from Roche Applied Science (Indianapolis, IN). For immunohistochemical staining, DRAQ5 ${ }^{\mathrm{TM}}$ and 4',6-diamidino-2-phenylindole (DAPI) were purchased from Sigma Chemical Co. Polyclonal gp60 antibody $(\mathrm{Ab})$ was prepared as previously described, ${ }^{24}$ and the fluorescent probe of cy3 derivative of anti-gp60 was prepared according to the existing protocol. ${ }^{25}$

\section{Cell culture}

PANC-1 cells (ATCC CRL 1649) were maintained in RPMI (Roswell Park Memorial Institute) medium containing 
$10 \%$ fetal bovine serum (FBS), at $37^{\circ} \mathrm{C}$, in a humidified atmosphere. For the experiments, cells were cultivated to confluence on $60 \mathrm{~mm}$ plates (BD Biosciences, Erembodegem, Belgium).

\section{Characterization of the cells}

For the microscopy analysis, PANC-1 cells were trypsinized and transferred to $35 \mathrm{~mm}$ plates at a density of $25 \times 10^{4}$ cells/dish. The cells were monitored by light microscopy (Olympus CKX 31, Munich, Germany).

\section{Noncovalent functionalization of CNTs with HSA}

MWCNTs (60 mg) were dispersed in a 3:1 (v/v) concentrated sulfuric and nitric acid mixture, and sonicated three times for 10 seconds each with a tip sonicator. Subsequently, the mixture was refluxed at $1200^{\circ} \mathrm{C}$ for 30 minutes. The oxidized MWCNTs treated in water solution were then centrifuged at $8000 \mathrm{rpm}$, to remove any large unreacted CNTs and metallic impurities from the solution. Finally, the oxidized MWCNTs were vacuum filtered through a $0.2 \mu \mathrm{m}$ polycarbonate filter (Whatman), until the elution was clear and had a neutral $\mathrm{pH}$. The filter cake was dried overnight at room temperature. After filtration, the solution concentration was re-estimated using ultraviolet-visible near-infrared (UV-Vis-NIR) spectroscopy (Jasco-V 530, Gross-Umstadt, Germany). One milligram of fluorescein isothiocyanate (FITC) $(10 \mathrm{mg} / \mathrm{mL}$ in dimethyl sulfoxide) was mixed with $50 \mathrm{mg}$ HSA in sodium buffer (20 mM, pH 8.5), followed by incubation for 2 hours in darkness, at room temperature, with continuous stirring. The HSA-FITC conjugate was purified by gel chromatography, using a Sephacryl 100-HR column eluted with $10 \mathrm{mM}$ phosphate buffered saline (PBS). ${ }^{30}$

Oxidized MWCNTs and HSA-FITC were mixed with deionized water at a concentration of $0.25 \mathrm{mg} \mathrm{mL}^{-1}$ and $1.25 \mathrm{mg} \mathrm{mL}^{-1}$, respectively. The mixture was sonicated for 1 hour with a tip sonicator under cooling in an ice bath, and then it was centrifuged for 5 minutes at $12000 \mathrm{rpm}$. The solids settled at the bottom of the centrifuge tube and consisted of unbound nanotubes, impurities, metals, and bundles of oxidized nanotubes. The resulting supernatant was collected and subjected to a second round of centrifugation. The collected supernatant contained the desired HSA-MWCNT conjugate.

Further, for a higher purification, the supernatant underwent gel chromatography for the purification process. Sephacryl 100-HR that was presoaked and deaerated using a vacuum pump was packed up to $15 \mathrm{~cm}$ in a
$2.5 \mathrm{~cm}$ diameter $\times 24 \mathrm{~cm}$ long glass column. The oxidized HSA-MWCNT supernatant recovered after centrifugation was layered on top of the gel and eluted using gravity water flow. Volume fractions were collected for 1-minute periods and analyzed for the presence of MWCNTs and HSA by measuring the absorbance at 500 and $280 \mathrm{~nm}$, respectively, using the spectrophotometer (Jasco V530, Gross-Umstadt, Germany). Fractions with protein content were pooled for further use. ${ }^{26}$

\section{Immunochemical experiments}

For experiments describing the selective internalization of HSA-MWCNT conjugates in PC cells via GP60 receptors (Figure 1), we have used freshly plated PANC-1 cells adhering to glass coverslips. By means of temperaturesensitive activation, PANC-1 cells have been exposed to cold $\left(4^{\circ} \mathrm{C}\right)$ incubation for 60 minutes, in $5 \mathrm{mg}$ HBSS (Hanks' balanced salt solution), mixed with cy3-labeled anti-gp60 Ab. Unlabeled anti-gp60 Ab were included in the incubation mixture at a 10 -fold molar excess $(5 \mu \mathrm{g} / \mathrm{mL})$ to prevent nonspecific adsorption of the fluorescent probe. The cells were washed twice with MWCNTs functionalized with HSA-FITC $(50 \mathrm{mg} / \mathrm{L})$ at $4^{\circ} \mathrm{C}$. Then, the cells were rewarmed to $37^{\circ} \mathrm{C}$ for 15 minutes, allowing the occurrence of antibody internalization. In order to remove the antibody adhering to the cell surface, the cells were further washed three times at 1-minute intervals with cold $\left(4^{\circ} \mathrm{C}\right)$ acetate buffer $(100 \mathrm{mM}$ $\mathrm{NaCl}, 50 \mathrm{mM}$ sodium acetate, $\mathrm{pH}$ 5.0). The cells immediately returned to $50 \mathrm{mg} / \mathrm{L}$ FITC-HSA-MWCNTs (pH 7.4). The coverslips were then transferred to the stage of a fluorescent microscope and examined for Cy3-labeled internalization.

Fluorescent staining procedures were performed in accordance with the manufacturer's protocol for each dye. Fluorescent images were acquired using a Zeiss LSM 710 confocal laser scanning unit equipped with argon and a $\mathrm{HeNe}$ laser mounted on a Axio Observer Z1 inverted microscope using 364, 488, and $568 \mathrm{~nm}$ excitation laser lines to detect DRAQ5 (BP590-650 nm emission), DAPI (BP385-470 nm
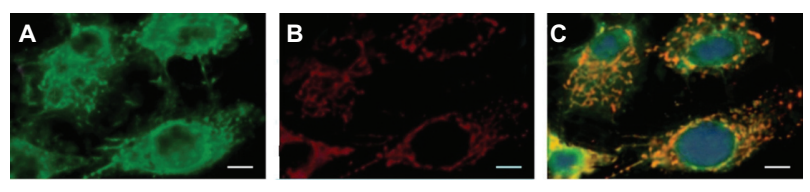

Figure I Selective targeting of GP60 receptors in pancreatic cancer cells. A, B) PANC-I cell monolayers were coincubated $\left(15\right.$ minutes at $\left.37^{\circ} \mathrm{C}\right)$ with FITC-labeled HSA-MWCNTs (15 mg/L) A) plus indocyanine (Cy3)-labeled anti-gp60 antibody B). C) Co-localization of the Cy3-gp60 antibody and FITC-HSA-MWCNTs. Scale bar: $5 \mu \mathrm{m}$. Results are representative of three experiments.

Abbreviations: FITC, fluorescein isothiocyanate; HSA, human serum albumin; MWCNT, multiwalled carbon nanotubes. 
emission), fluorescein isothiocyanate (FITC) (BP505-550 emission), and Cy3 fluorescence (LP585 emission), respectively.

\section{PC harvesting}

Six patients diagnosed with adenocarcinoma of the body of pancreas were referred to the 3rd Surgery Clinic, Cluj-Napoca, Romania, for surgical treatment. In view of a localized pancreatic neoplasm, surgical removal of the tumor was planned for each patient. Each pancreatic tumor was found by palpation on the left side of the portal vein during laparotomy. This was confirmed by intraoperative ultrasonography, which showed hypoechogenic, well defined tumors, located between the isthmus and the corpus of the pancreas. The other parts of the pancreas appeared to be normal. Left splenopancreatectomy (distal pancreatectomy and splenectomy) with splenic, celiac, and hepatic lymphadenectomy was performed after the intraoperative identification and preparation of the splenic artery and vein.

\section{Pancreas preservation}

Each specimen (the body and tail of the pancreas and the spleen) was transported in a sterile bag containing Custodiol solution, sealed with an adhesive strip, and placed in a second container which was also filled with Custodiol perfusion solution in order to avoid any failure of cooling by trapped air. Each specimen was safety ensured by the double packing, placed in a sterile plastic container, and the lid securely closed. The plastic container was further placed in a cooling box containing ice for the transportation from the surgery room to the laboratory.

Further, each specimen was immersed in a water bath for accurate temperature control at $5.5^{\circ} \mathrm{C}$, filled with lactated Ringer's solution (a crystalloid solution with a composition physiologically closer to that of plasma than $0.9 \%$ saline).

Custodiol solution, used for perfusion and flushing of donor pancreas in transplantology, was perfused through an appropriately prepared air-free perfusion tube system into the splenic artery located in the upper edge of the pancreas (at a flow rate of $1.5 \mathrm{~mL}$ per minute and per gram - the estimated weight of the specimen was between 80 and $110 \mathrm{~g}$ ).

Separately, $50 \mathrm{~mL}$ of HSA-MWCNT solution $(200 \mathrm{mg} / \mathrm{L})$ diluted with $50 \mathrm{~mL}$ Custodiol was administered by gravity perfusion (the container was placed $1 \mathrm{~m}$ above the level of the bath, the perfusion rate flow was of $0.5 \mathrm{~mL} / \mathrm{s}$ ) in the greater pancreatic artery (a blood vessel that arises from splenic artery), under Doppler ultrasound guidance (Figure 2), to

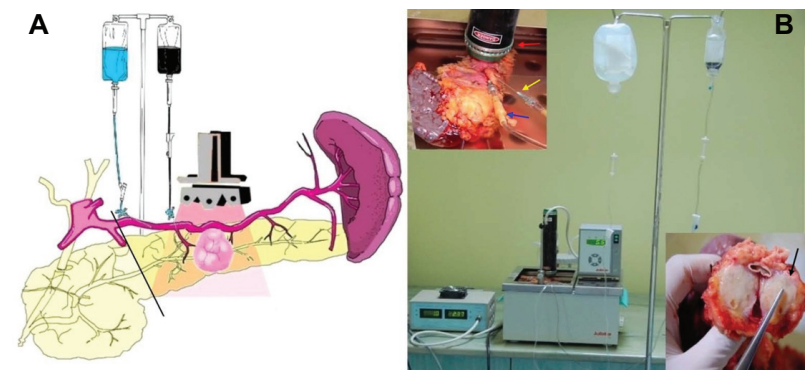

Figure 2 A) Schematic illustration of the ex-vivo thermal ablation of human pancreatic adenocarcinoma on surgically resected specimens from the body and tail of the pancreas and spleen. B) The proposed system of ex-vivo laser ablation of human pancreatic cancer cells (red arrow, laser diode placed above the tumoral mass; blue arrow, the intra-arterial administration of HSA-MWCNT-FITC in the pancreatic magna artery; yellow arrow, the intra-arterial administration of Custodiol solution in the splenopancreatic artery; black arrow, macroscopic aspect of tumor mass after photothermal treatment).

Abbreviations: FITC, fluorescein isothiocyanate; HSA, human serum albumin; MWCNT, multiwalled carbon nanotubes.

safely allow the flushing of the pancreatic "capillary bed" with HSA-MWCNT solution.

The length of the ex-vivo experiment was of about 5 hours for each specimen, much less than the maximum time recommended (12-15 hours) for the preservation of the living pancreas during transplantation. ${ }^{27}$

\section{Laser irradiation}

A diode laser was fixed above the organ bath in a permanent position while the living pancreas was being kept immersed and perfused, as shown in Figure 2B. For the laser positioning above the malign lesion, ex-vivo ultrasound was performed on the surgical specimen. Thus, the laser diode was vertically placed $1 \mathrm{~cm}$ above the edge of the pancreas $(1-3 \mathrm{~cm}$ above the hypoechogenic image inside the pancreatic parenchyma, depending on the morphological particularity of each lasertreated specimen). We irradiated the pancreatic parenchyma containing the tumor mass for 30 minutes, using a $5 \mathrm{~W} / \mathrm{cm}^{2}$, $808 \mathrm{~nm}$ continuous laser generator (Apel Laser, Bucharest), in combination with the continuous intra-arterial administration of HSA-MWCNT-Custodiol solution.

\section{Measurement of heat shock protein (HSP) expression}

Specimens from various areas (both tumor and healthy tissue) were harvested after combined intra-arterial administration and external laser irradiation, and embedded in OCT cryomatrix (Sakura Finetek). Fluorescence immunostaining was performed on several sections for the measurement of HSP27 (green fluorescence) and HSP90 (red fluorescence) expression. 


\section{Tissue staining and imaging}

For this purpose, multiple tissue samples were extracted from each region and from each surgical specimen, under ultrasound guidance. Thus, biopsy samples before, during, and after irradiation and treatment with HSA-MWCNTs were obtained from the tumor (central and peripheral area) and from the surrounding pancreatic tissue $(5-10 \mathrm{~mm}$ outside the gross margins of the tumor), using TruCut needle (Dyna Medical, ON, Canada) biopsy.

Biopsies were immediately frozen in liquid nitrogen, stored at $-70^{\circ} \mathrm{C}$, and sectioned at $7 \mu \mathrm{m}$ with a Leica $\mathrm{RM}$ 2125 RT microtome (Wetzlar, Germany).

For the common histopathologic analysis, tissue specimens harvested from the tumor mass and the surrounding areas were immersed in $4 \%$ formaldehyde solution, after the photothermal treatment. The tissues were embedded in paraffin wax, serially sectioned, and stained with hematoxylin and eosin. Typical morphological characteristics were examined under light microscope. Thermal injury was assessed in sections using a semiquantitative scale, with a necrotic area percentage of $0=$ normal; $1=<10 \% ; 2=10 \%-50 \% ; 3=50 \%-75 \%$; $4=>75 \%$. Light microscopy analysis was performed using an Olympus BX60 microscope (Hamburger, Germany).

\section{Electron microscopic observation}

Biopsies specimens were extracted from several parts of the tumor and routinely prepared on $0.05 \mathrm{~mm}$ thin slides, monitoring the changes in the malignant tissue's ultrastructural morphology, using a Jeol JEM 1010 transmission electron microscope (Jeol, Tokyo, Japan). The images were captured using a Mega VIEW III camera (Olympus, Soft Imaging System, Münster, Germany).

\section{Temperature measurements}

To characterize the baseline conditions and parameters for the proposed treatment method, continuous remote multithermometer reading was conducted in both the healthy and tumor tissue during the treatment, using a fast response Therma 20 handheld thermometer (Electronic Temperature Instruments, Worthing, UK), equipped with stainless steel, fast response, needle penetration probe. The thermistor probes were positioned inside the healthy or tumor tissue under ultrasound guidance.

\section{Statistical methods}

The continuous data was tested for normality (KolmogorovSmirnov test) before the hypothesis testing. The longitudinal data, representing repetitive measurements of the same parameter during the follow-up interval, were analyzed through the construction of kinetic curve along with the area under the curve (AUC) calculus. Consecutively, kinetic curves of two different groups were compared using MannWhitney $U$ test. Fisher's exact test was used for qualitative data correlations. For all tests, a 0.05 threshold was selected for statistical significance. Statistical data analysis was performed using SPSS 17.0 software (Chicago, IL).

\section{Results and discussion} Functionalization of MWCNTs with HSA

To obtain a targeted delivery of MWCNTs directly into the cancer cells, and to visualize and detect the localization of the nanotubes inside the cells, HSA-FITC was used and noncovalently labeled onto the oxidized surface of MWNTs.

Confocal microscopy has been proposed to identify fluorescein isothiocyanate (FITC) labeled CNTs in solution and to provide clues regarding the successfulness of noncovalent functionalization of MWCNTs with HSAFITC. As shown in Figure 3C, globular green MWCNTs, corresponding to large molecules of fluorescent albumin, were observed.

The oxidation of the nanotubes using a $3: 1(\mathrm{v} / \mathrm{v})$ mixture of concentrated sulfuric and nitric acid gives them hydrophilicity and stability in aqueous systems due to the formation of $-\mathrm{COOH}, \mathrm{OH}$ groups at the end of and along the sidewalls of the tubes. ${ }^{28}$

Fourier transform infrared (FTIR) spectra from Figure 4A confirms successful oxidation. By comparing the FTIR spectra of pristine MWCNTs (black) with the oxidizedMWCNTs (red), the characteristic bands of the oxygencontaining groups appear at $3422 \mathrm{~cm}^{-1}$, corresponding to the $\mathrm{O}-\mathrm{H}$ stretching vibration, ${ }^{29}$ a week band at $1721 \mathrm{~cm}^{-1}$, corresponding to the carbonyl and carboxyl $\mathrm{C}-\mathrm{O}$ stretching vibration, at 1582 and $1380 \mathrm{~cm}^{-1}$, corresponding to the $\mathrm{O}-\mathrm{H}$ deformation vibration, and at $1117 \mathrm{~cm}^{-1}$, corresponding to the $\mathrm{C}-\mathrm{O}$ stretching vibration. The band at $620 \mathrm{~cm}^{-1}$ corresponds to the $\mathrm{C}-\mathrm{O}$ out-of-plane deformation. ${ }^{30}$

Further, we have noncovalently conjugated HSA-FITC on the surface of oxidized MWCNTs. Firstly, we have covalently labeled HSA with FITC at an increased $\mathrm{pH}$ (above $\mathrm{pH}=9$ ), as schematically shown in Figure 3A. FITC has covalently attached to the protein through the alpha-amino group. Secondly, HSA-FITC complex has been adsorbed onto the nanotubes, presumably through electrostatic 
A
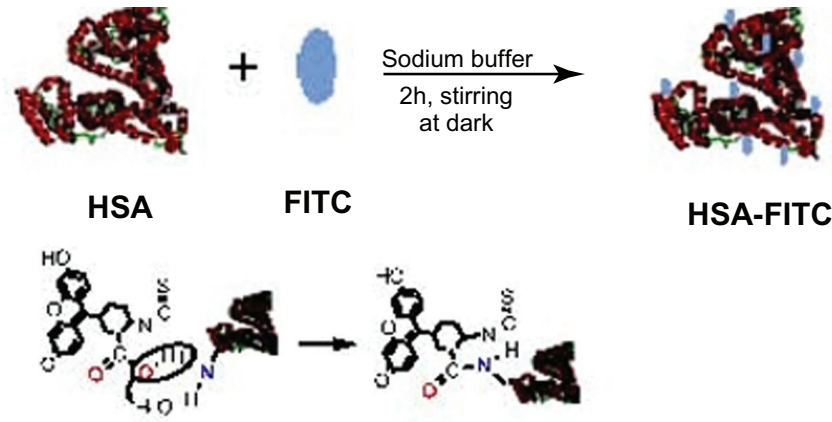

B

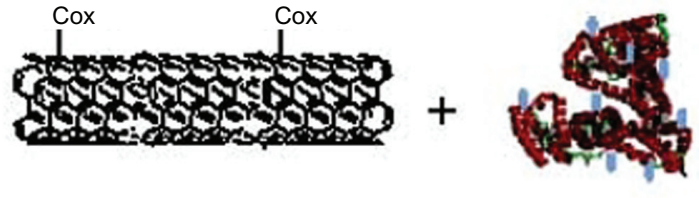

HSA-FITC

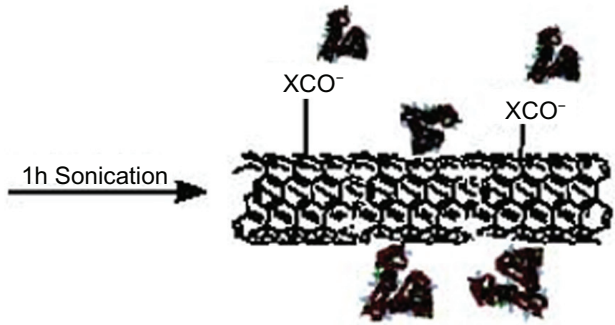

Cox $=$ Oxigen-containing surface groups

Oxidized MWCNTs

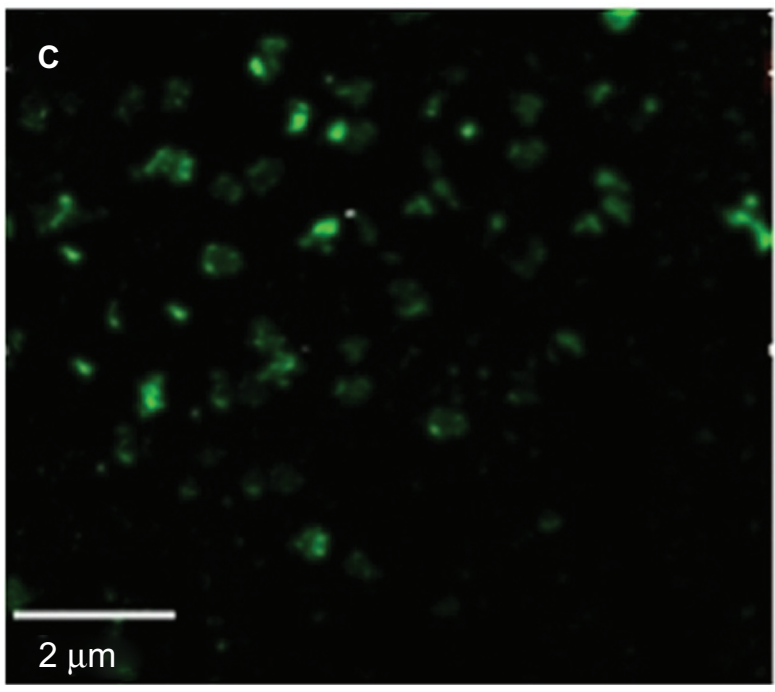

HSA-FITC

Oxidized MWCNTs-HSA-FITC

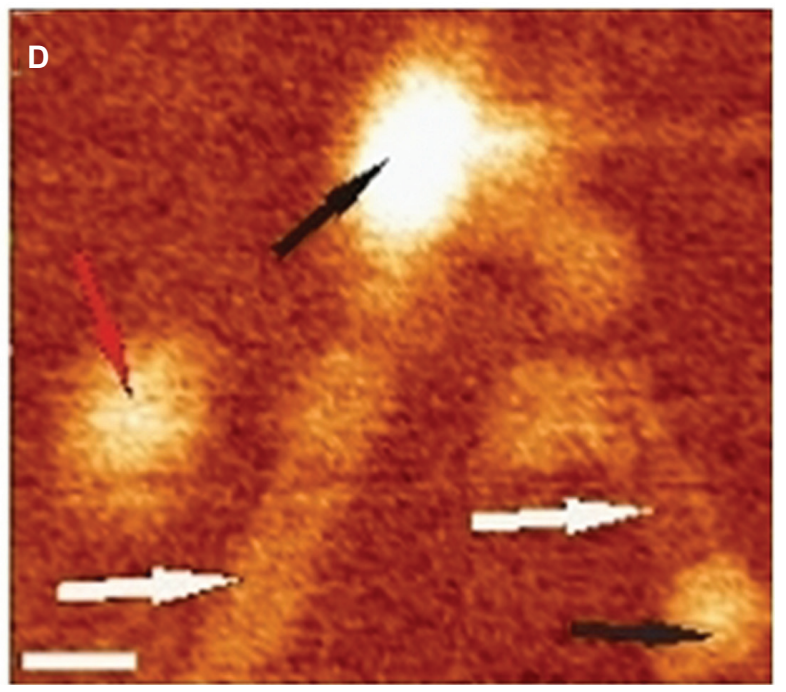

Figure 3 A) Illustration of chemical reactions used for the covalent labeling of HSA-FITC. B) Schematic showing oxidized MWCNT-HSA-FITC formation. C) A typical fluorescent image of HSA-MWCNTs (100 mg/L): globular fluorescent carbon nanotubes corresponding to attached large molecule of fluorescent albumin are observed. D) $140 \mathrm{~nm} \times 120 \mathrm{~nm}$ AFM topographic image of HSA (black arrows) conjugated to MWCNTs (white arrows). The red arrow indicates the presence of an unconjugated HSA molecule. The scale bar represents $20 \mathrm{~nm}$.

Abbreviations: AFM, atomic force microscopy; FITC, fluorescein isothiocyanate; HSA, human serum albumin; MWCNT, multiwalled carbon nanotubes.

interactions between the functional groups of MWCNTs and the protein-positive domains (Figure 3B). Taking into consideration the fact that not all the surface of the nanotubes is oxidized, hydrophobic interactions can also occur.

UV-Vis spectroscopy is a simple but efficacious method which confirms the formation of the oxidized MWCNTHSA-FITC complex. The nanotube solutions give an adsorbtion band at $295.7 \mathrm{~nm}$, which corresponds to the $+/$-plasmon transition of MWCNTs. ${ }^{31}$

The yellowish HSA-FITC solution has the characteristic adsorbtion band at $489 \mathrm{~nm}$ and a second adsorbtion at $292 \mathrm{~nm}$, which suggests the existence of aromatic amino acids of HSA. Comparing the above mentioned spectra, the formation of the MWCNT-HSA-FITC complex becomes obvious due to the appearance of oxidized-MWCNT band and HSA-FITC band at $475.6 \mathrm{~nm}$, which is shifted and has low intensity (Figure 4C).

The conjugation of HSA-FITC onto the nanotube surface is also confirmed by FTIR spectroscopy as seen in Figure 4B. No similarity can be observed when comparing the spectra of HSA-FITC with that of the nanotube-conjugated HSA-FITC. All the corresponding peaks had shifted their position, and some of them even disappeared. In the higher region, the stretching vibration band of the $\mathrm{N}-\mathrm{H}$ groups at $3409 \mathrm{~cm}^{-1}$ 

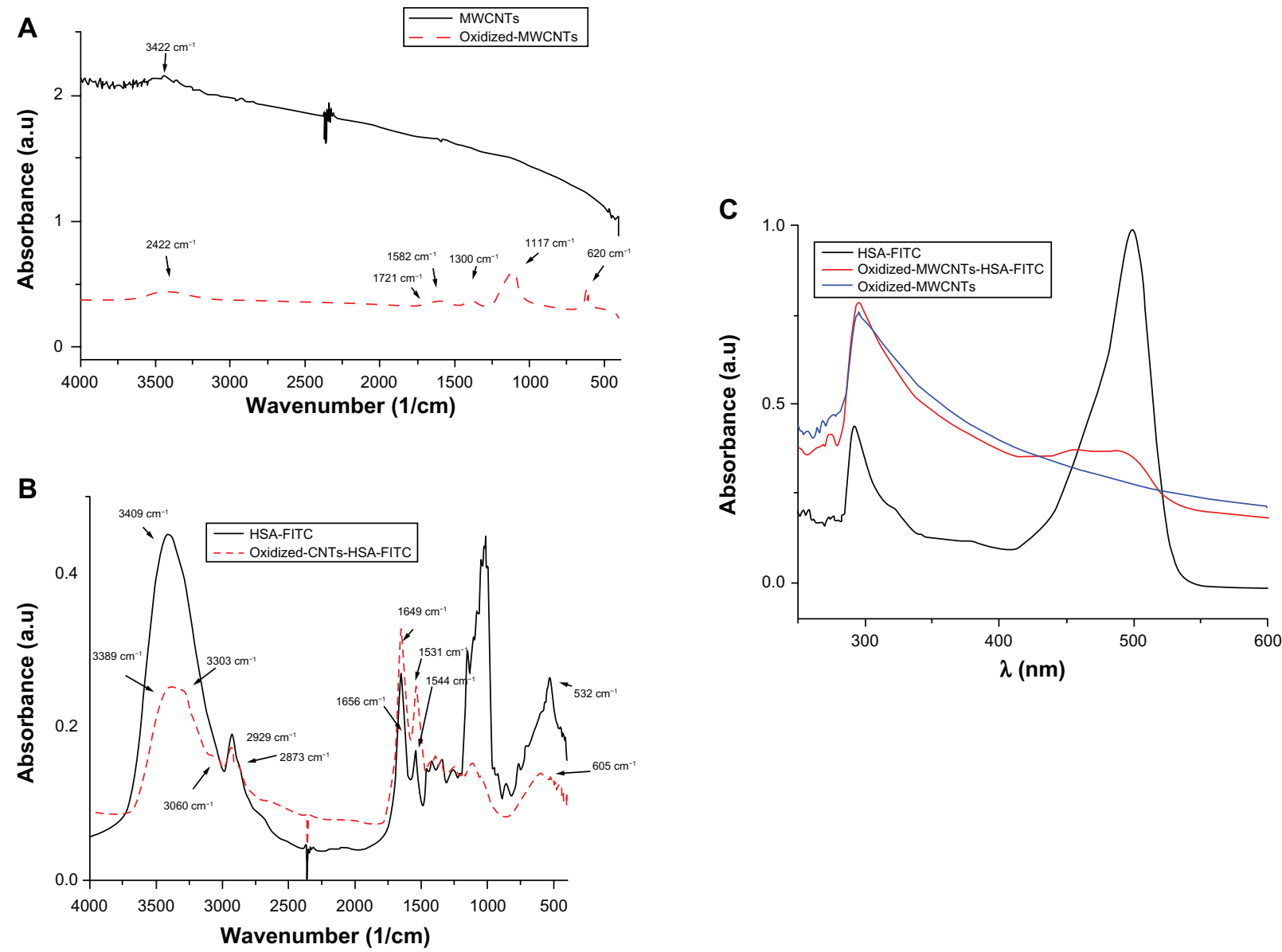

Figure 4 A) FTIR spectra of pristine MWCNTs and oxidized MWCNTs. B) FTIR spectra of HSA-FITC and HSA-FITC-coated oxidized MWCNTs. C) UV-Vis absorption spectra of HSA-FITC (black), oxidized-MWCNTs (blue), and oxidized-MWCNT-HSA-FITC (red).

Abbreviations: a.u, absorbance units; FITC, fluorescein isothiocyanate; FTIR, Fourier transform infrared; HSA, human serum albumin; MWCNT, multiwalled carbon nanotubes; UV-Vis, ultraviolet-visible.

changed their shape in a broad band that included two peaks: one at $3389 \mathrm{~cm}^{-1}(\mathrm{~N}-\mathrm{H}$ groups stretching vibration $)$ and the second at $3303 \mathrm{~cm}^{-1}$, which is the pyridine aromatic $\mathrm{C}-\mathrm{H}$ stretching vibration band. The aliphatic $\mathrm{C}-\mathrm{H}$ stretching vibration band at 2929 and $2873 \mathrm{~cm}^{-1}$ moved to 2922 and $2865 \mathrm{~cm}^{-1}$, showing that these groups are involved in electrostatic bonds. Amide I and II are also shifted to low frequency: amide I from 1656 to $1649 \mathrm{~cm}^{-1}$, amide II from 1544 to $1532 \mathrm{~cm}^{-1}$. The $\mathrm{CH} 3$ asymmetric and symmetric deformation changed their band from 1459 to $1447 \mathrm{~cm}^{-1}$, and from 1416 to $1389 \mathrm{~cm}^{-1}$. The region in between dramatically changed their intensity. This is due to the spontaneous adsorbtion of the crystalline HSA-FITC complex onto the MWCNTs and the formation of a well organized oxidized MWCNT-HSA-FITC.

Furthermore, atomic force microscopy (AFM) analysis of the HSA-MWCNT solution was performed. A representative AFM evidence of the successful attachment of HSA molecules onto the surface of the nanotubes is shown in Fig- ure 3D. AFM allowed the analysis at the nanometric scale of the two HSA molecules (black arrows in Figure 3D) attached to the end of the nanotubes (white arrows). A single HSA molecule (red arrow) has been also observed in the topographic image shown. The length of the CNTs was estimated as being lower than $200 \mathrm{~nm}$. The lateral resolution of an AFM image is determined by the tip of the object that is imaged. In the presented image, the width of the nanotube appears to be greater than $2 \mathrm{~nm}$, as we used an AFM tip having a $\sim 15 \mathrm{~nm}$ radius of curvature.

\section{Ex-vivo testing procedure}

The main goal of this investigation was to develop and test a new method of treatment of human pancreatic adenocarcinoma. Preliminary literature data supports the involvement of albumin in tumor growth. In the present study, we tested a carrier-linked CNT system based on HSA for the selective delivery and laser mediated ex-vivo ablation of living human PC tissue (Figures 2A and 2B). 
The central hypothesis of the study was that albumin will carry the MWCNTs inside the tumor tissue after intraarterial perfusion. To test this hypothesis, we developed an experimental platform using viable resected specimens from patients who underwent curative treatment of PC.

Despite their attractiveness in nanomedicine, in-vitro test conditions cannot duplicate the host environment due to the variability of the testing media (eg, acidic versus alkaline, differences in cation content), and exhibit limiting effect of protein binding on cell surface receptors. ${ }^{32}$ Moreover, the controlled conditions present in in-vitro biosystems are significantly different from those in vivo, and properties of nanoparticles such as high adsorption capacity, hydrophobicity, surface charge, optical and magnetic properties, or catalytic activity may be modified. ${ }^{33}$

On the other hand, obvious potential pitfalls of nanophotothermolysis experiments on mice models are represented by the morphology and size of the tumor, which are fundamentally different than that of human tumors. Thus, all the particularities of human tumors such as vessel anatomy and distribution, and volume and location, are not comparable to these models.

\section{Cytotoxicity induced by laser irradiation or internalization of HSA-MWCNTs}

To avoid a potential bias, we investigated the possible necrotic effect of simple laser irradiation. For this purpose, using fine needle biopsy, we extracted tumor samples before and after irradiation, without HSA-MWCNTs. As shown in Figures 5A and 5B, no differences regarding size and shape, nuclear modifications or necrosis, were observed at the histopathological analysis of the specimens, before and after irradiation. For similar reasons, we analyzed tumor specimens after the simple internalization of HSA-MWCNTs. As shown in Figure 5C, no morphological changes were noticed in the extracted samples after administration.

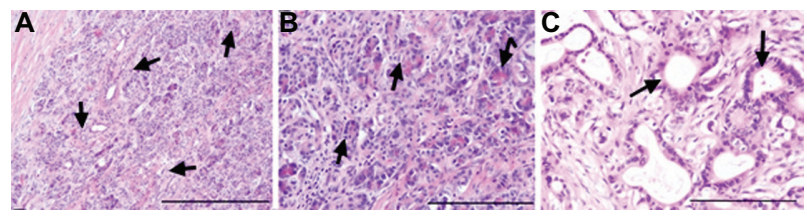

Figure 5 Preserved tumoral architecture after laser treatment or HSA-MWCNT administration. A) Before irradiation/administration: tumoral structures infiltrating between normal pancreatic acini (black arrows) H\&E stain, obxl00, (scale bar represents $400 \mu \mathrm{m}$ ). B) After irradiation: normal pancreatic acini with chromatic polarity and infiltrating tumoral structures (black arrows) H\&E stain, obx200 (scale bar represents $400 \mu \mathrm{m}$ ). C) After HSA-MWCNT administration: normal tumoral duct structures lined by a single layer of polymorphic columnar cells surrounded by the desmoplastic stromal reaction (black arrows) H\&E stain, obx200 (scale bar represents $200 \mu \mathrm{m})$. Results are representative of three experiments.

Abbreviations: H\&E, hematoxylin and eosin stain; HSA, human serum albumin; MWCNT, multiwalled carbon nanotubes.
In addition, terminal TUNEL assay was performed, suggesting that there was no difference regarding the apoptotic rate among the examined tissues (data not shown).

\section{Internalization of CNTs}

The ability of FITC-labeled bioconjugate of HSA-MWCNTs to internalize inside the tumor cells after administration via vascular supply has been assessed by confocal fluorescence and electron microscopy imaging.

The area with the highest concentration of HSA-MWCNTs was observed in the central part of the tumor, where most of the malignant cells were stained with fluorescent dye (Figure 6C). The malignant tissue extracted from the periphery of the tumor also presented intracytoplasmic MWCNTHSA-FITC. However, a lower density of fluorescent nanotubes was noted compared with the central region of the tumor (Figure 6B). No fluorescence was observed outside the tumor in the surrounding healthy parenchyma (Figure 6A). Thus, we have provided imagistic evidence that HSA can act as delivery carrier of MWCNTs, and because we were unable to identify any fluorescence in the healthy pancreatic tissue, we reasoned that the HSA-MWCNT bioconjugates exhibit $100 \%$ affinity for ductal adenocarcinoma cells. These data
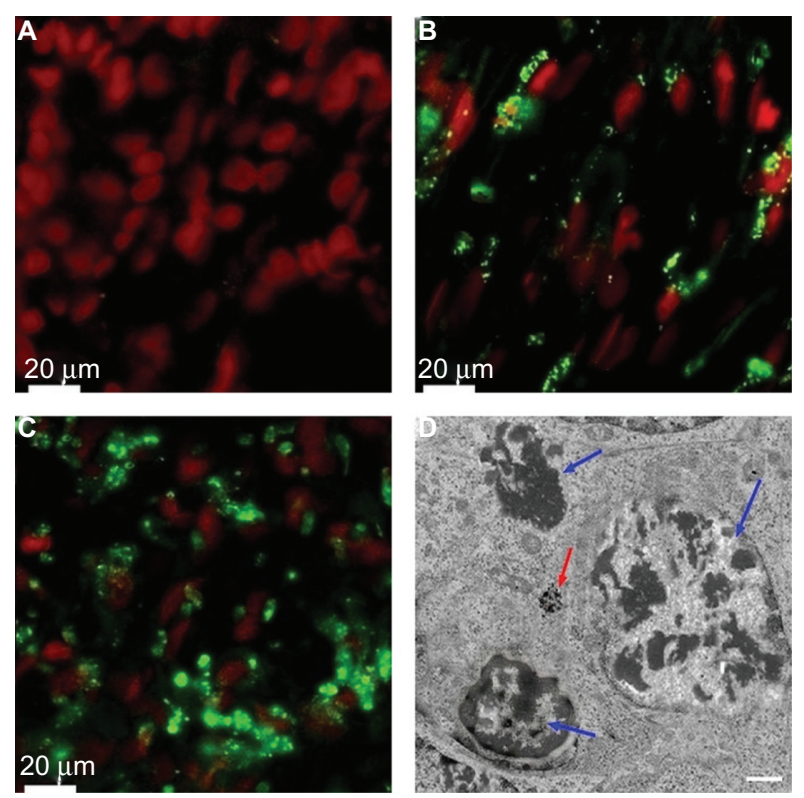

Figure 6 Confocal imaging of the tissue samples after intra-arterial FITC-HSAMWCNT administration (A-C). Electron microscopy of tumor tissue after HASMWCNT-mediated photothermal treatment. A) Surrounding pancreatic tissue. B) Peripheral area of the tumor. C) Central region of the tumor (red, nuclei stained by DRAQ5 ${ }^{\mathrm{TM}}$ coloration; green, intracellular FITC-HSA-MWCNTs). Results are representative of three experiments. D) Electron microscopy demonstrates necrotic features with disintegrated nuclei in the tumor tissue after treatment (blue arrows). Intracellular clusters of MWCNTs could also be demonstrated (red arrows). Scale bar: $2 \mu \mathrm{m}$.

Abbreviations: FITC, fluorescein isothiocyanate; HSA, human serum albumin; MWCNT, multiwalled carbon nanotubes. 
support on the one hand the involvement of the vascular architecture of the malignant lesion tributary to pancreatic magna artery and on the other hand the specificity of HSA for cell receptors in the selective internalization of HSAMWCNTs.

Moreover, electron microscopy of the tissue after treatment showed necrotic features with disintegrated nuclei, and intracellular clusters of MWCNTs, suggesting the efficacy of nanophotothermal ablation.

\section{The mechanism of selective internalization of HSA-MWCNTs inside the malignant pancreatic cells}

To shed light on the molecular mechanisms involved in the specific internalization of HSA-MWCNTs in the pancreatic malignant cells, we investigated the possibility that a $60 \mathrm{kDa}$ glycoprotein, gp60, which is known to function in albumin transcytosis in malignant cells, ${ }^{34}$ was involved in the selective internalization of albumin bound to CNTs. To accomplish this, we let the cells treated with $5 \mathrm{mg} / \mathrm{L}$ HSA-MWCNTs for 1 hour incorporate cy3-anti-gp60 antibody for 30 minutes at $37^{\circ} \mathrm{C}$. Therefore, we obtained fluorescent images proving the internalized cy3 fluorescence (Figure 1B).

Alternatively, we showed that PANC-1 cells internalized albumin-bound MWCNTs (fluorescently labeled with FITC) that were distributed into the punctate structure inside the cells (Figure 1A). DAPI, which is known to form fluorescent complexes with natural double-stranded DNA, was used for nuclei staining. In Figure 1C, a nearly complete co-localization of the FITC fluorescence (green image) and cy 3 fluorescence (red image) was emphasized by the yellow color in the merged image. This finding suggests that albumin-bound MWCNTs were incorporated into the plasmalemmal vesicles containing gp60 as a membrane protein, further validating HSA-MWCNT specificity for gp60 receptors. Therefore, based on this data, we showed that HSA-MWCNTs can act as specific and sensitive sitetargeted nanosystems against gp60 receptors located on the PC cell membranes.

Very recent clinical trials suggest that specific targeting of GP60 (albondin) receptor with Abraxane (Celgene, Summit, USA), a cytostatic drug called paclitaxel bound to human albumin may prolong the survival in advanced cases of PC. ${ }^{35}$ For the first time, the results of this study demonstrate that HSA-MWCNTs exploit the albondin receptor, in a similar manner, penetrating the blood-stroma barrier with consequent delivery of active nanomaterial inside the malignant cells (Figure 7).

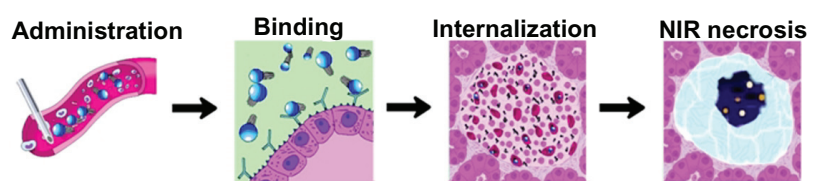

Figure 7 Schematic illustration of HSA-MWCNT-mediated ablation of pancreatic cancer.

Abbreviation: NIR, near infrared.

\section{Temperature measurements}

Laser irradiation of cancer cells labeled with HSA-MWCNTs may be used in two modes: pulse and continuous. The pulse mode produces localized (few micrometers) damage of individual cancer cells by laser-induced micro- and nanobubbles around overheated nanoparticles, without harmful effects on the surrounding healthy cells. It particularly favors in-vivo destruction of single circulating tumor cells only by using nanosecond laser pulses. The second mode is more time consuming (a few minutes of exposure) and has the thermal denaturation and coagulation effects as main mechanisms of cell damage. It is more appropriate to treat primary tumors with sizes of several millimeters. ${ }^{36}$ Based on these data, we used continuous laser to irradiate the tumor after the internalization of HSA-MWCNTs.

There was no difference in tissue temperature among the three areas measured at baseline (Figure 8): 1) the central region of the tumoral mass; 2) the peripheral region, 2-5 $\mathrm{mm}$ away from the edge of the hypoechogenic tumor mass; and 3) the healthy pancreatic tissue surrounding the tumor. Statistical analysis of the maximal tissue temperature among the three areas revealed that the heating curves of the area under the curve (AUC) corresponding to the central and peripheral regions of the tumor were significantly higher $(P>0.05)$ than the heating curves obtained from the temperature measurements in the pancreatic tissue. This indicates that the heating process following the irradiation and HSA-MWCNT treatment mainly occurred in the tumor mass. As shown in Figure 8B the maximal tissue temperatures $\left(4.2^{\circ} \mathrm{C}\right.$ in the surrounding healthy tissue; $25.6^{\circ} \mathrm{C}$ at the periphery of the tumor; $29.3^{\circ} \mathrm{C}$ in the central region of the tumor) were approximately achieved after 20 minutes of irradiation combined with the simultaneous administration of HSA-MWCNTs. The findings in Figure 8 demonstrate that after 20 minutes of laser irradiation combined with ex-vivo intra-arterial administration, the temperature elevations in the tumor tissue are high enough to produce extensive necrosis of the tumor compared with the harmless effects on the healthy parenchyma. In a separate experiment, $200 \mathrm{mg} / \mathrm{L}$ of highly purified solution of unconjugated MWCNTs were 
A

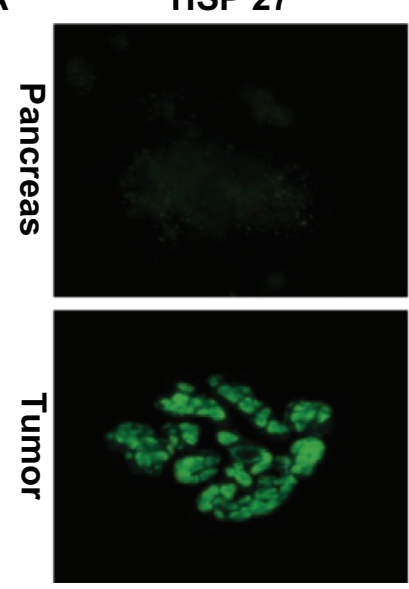

HSP 90
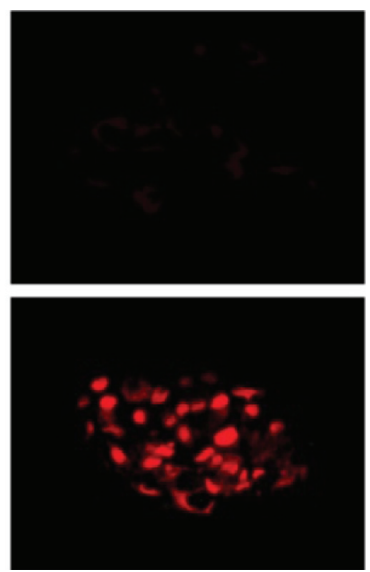

B

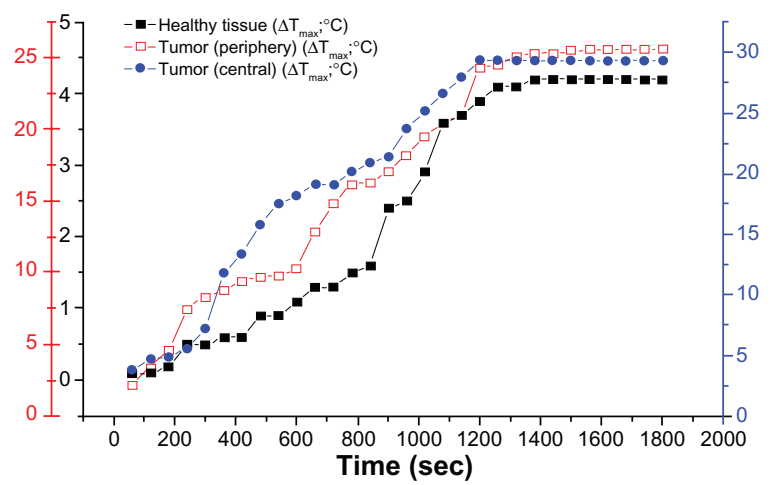

Figure 8 Thermal response to HSA-MWCNT-mediated photothermal therapy. A) The top row of images depicts basal level of expression of HSP27 (green) and HSP90 (red) in healthy, surrounding tissue. The lower row of images depict HSP expression in tumor sections. B) 3 Y-plot chart of time-temperature curves obtained from the healthy and malign tissue, with use of the thermistors.

Abbreviation: HSP, heat shock protein.

simultaneously administered in combination with external laser irradiation. Temperature measurements displayed a maximal increase (delta $\mathrm{t}=16.6^{\circ} \mathrm{C}$ ) in the superficial pancreatic tissue above the tumor (closest to the laser diode). Moreover, the temperature magnitude at the periphery of the tumor closest to the laser beam was of only $9.7^{\circ} \mathrm{C}$, while in the middle and distant margins of tumor the increase was of only $6.2^{\circ} \mathrm{C}$ and $4.5^{\circ} \mathrm{C}$ respectively. These changes were further confirmed by the histopathological analysis displaying extensive necrotic areas in the healthy tissue located in the vicinity of the laser diode, as suggested by the histological scores (Figure 9E). Thus, we obtained evidence that ex-vivo intra-arterial administration of highly purified unconjugated MWCNTs is tributary to the architecture of the capillary bed inside the pancreatic parenchyma, further demonstrating the nonselective distribution of the nanomaterial inside the pancreatic tissue (both healthy and malignant).

Remote thermistors may be independently placed inside the tissue, and can measure intraprocedural tissue temperatures. In the present study, the CNT mediated thermal activation of tissues was similar to that reported by other papers. $^{37}$

\section{HSP response to MWCNT-mediated photothermal therapy}

To confirm the results mentioned above, we have used an independent measure of heat generation: induction of HSPs, which are induced by elevated temperatures and serve as endogenous cellular markers of thermal stress. As seen in Figure 8A, minimal expression exists for all HSPs in the surrounding tissue, after treatment. Maximal HSP27 and HSP90 expression were induced in the tumor tissue.

\section{Assessment of tumor necrosis after laser treatment and internalization of HSA-MWCNTs}

In the present study, we have used MWCNTs as heat inducing agents under laser radiation, in order to obtain a selective necrosis of the malignant lesion. This method is based on the presence and clustering of MWCNTs inside the targeted cells. Their highly optical absorption capacity is responsible for inducing thermal effects under NIR irradiation, where the biological systems have low absorption and high transparency. ${ }^{38}$ The optoelectronic transitions in the graphitic structures of the MWCNT clusters generate thermal energy ${ }^{39}$ that rapidly diffuses into the subcellular compartments where the nanobioconjugates are present.

In this ex-vivo experiment, the pancreas was preserved in crystalloid perfusion combined with cold storage. Simultaneously, HSA molecules bound to MWCNTs were directly perfused in the greater pancreatic artery under ultrasound guidance. The next step was to irradiate the hypoechogenic tumor mass.

After combined irradiation and intra-arterial perfusion of HSA-MWCNTs, all sections were evaluated in detail for any cell shape changes (cell shrinkage, extraordinary cytoplasmic eosinophilia, clear cell change, cytoplasmic vacuolization), nuclear changes (nucleomegaly, multinucleation, hyperchromasia, symplastic changes), and coagulative necrosis. The histopathological examination clearly revealed foci 


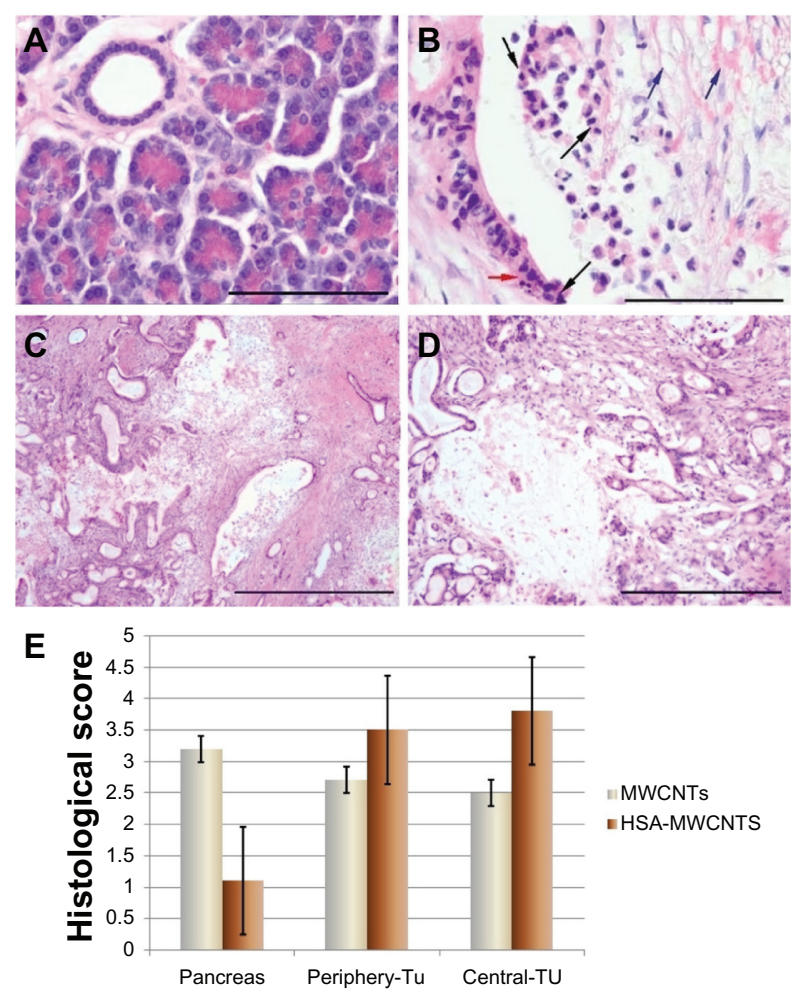

Figure 9 Histopathological aspects of the tissue after HSA-MWCNT intraarterial administration and laser irradiation. A) Surrounding pancreatic tissue after irradiation. Normal acinar cells with staining polarity and pancreatic duct lined by cuboidal epithelium. No structural changes were observed. H\&E stain, obx400 (scale bar represents $100 \mu \mathrm{m})$. B) Tumoral duct after irradiation. Distortion of the tumor structures, with loss of cell contact, piknotic and fragmented nuclei (black arrows); edematous extracellular matrix, disrupted, intense acidophilic fibers of collagen (blue arrows); apoptotic bodies (red arrow). H\&E stain, obx40 (scale bar represents $100 \mu \mathrm{m})$. C) Periphery of the tumor. Foci of thermal lysis consisting of destructed tumoral ducts and desmoplastic reaction structures. H\&E stain, obx4 (scale bar represents $1000 \mu \mathrm{m})$. D) Central area of the tumor. An extensive region of thermal lysis of cancer cells can be observed. H\&E stain, obxl0 (scale bar represents $400 \mu \mathrm{m}$ ). E) Histological scores of necrosis in healthy and malign tissue. Thermal injury was assessed in sections using a semiquantitative scale in which the percentage of necrotic areas was assigned a score: $0=$ normal; $1=<10 \% ; 2=10 \%-50 \%$; $3=50 \%-75 \% ; 4=>75 \%$. Results are representative of three experiments.

Abbreviations: H\&E, hematoxylin and eosin stain; HSA, human serum albumin; MWCNT, multiwalled carbon nanotubes.

with sizes ranging from $500 \mu \mathrm{m}$ to a few millimeters, with common signs of thermal cell necrosis, present in all the examined malignant slides in the entire tumor mass, mostly in its central area.

A representative histopathological image of such necrosis is shown in Figure 9C: the malignant cells are shrunken, with loss of contact, eosinophilic cytoplasm and nuclear damage (pyknotic and fragmentized nuclei). The apoptotic bodies were present (Figure 9B). At the same time as the destruction of the tumor cells, thermal injury was observed in the stromal reactive tissue. Both the extracellular matrix and the cellular components of the desmoplastic reaction were affected. As shown in Figure 9B, the connective tissue surrounding the tumor cells was disrupted (oedematous), with fragmented, acidophilic collagen fibers. Some foci revealed hydropic degeneration, with cell ballooning due to intracitoplasmatic vacuolization of the tumor cells (Figure 9B). Due to the impaired staining characteristics, no clear demarcation between the viable and necrotic cells was observed. Figure 9D shows few areas of preserved tumoral architecture, with tumoral and glandular structures lined by mucus-secreting columnar cells alternating with thermally damaged, shrunken cells. No morphologic changes were noticed during the histopathological analysis of the samples extracted from the pancreatic tissue surrounding the tumor. Figure 9A illustrates the histological characteristics of this tissue after photothermal treatment. Normal pancreatic structure with secretory units or acini consisting of a single layer of pyramidal cells, surrounded by connective tissue, Langerhans islets and pancreatic ducts could be observed. These findings were additionally confirmed by electron microscopy analysis.

Histological scoring indicated that pancreatic damage was more pronounced in malign tissue after treatment. As seen in Figure 9E, overall histological scores showed a marked increase in malign cell death (where necrotic areas were more than $50 \%$, on all the examined slides), whereas necrotic cells were observed only sporadically in tissue obtained from healthy, surrounding parenchyma. For control solution, tissue disruption and cell death was observed predominantly in the surrounding tissue. These data, together with the observation of massive HSA-MWCNT accumulation in the tumor tissue, suggest that the combination of HSA-MWCNTs and laser irradiation produces selective necrosis of human PC.

To investigate the selectivity and efficacy of the proposed treatment, terminal TUNEL assay was performed in order to stain the necrotic nuclei of apoptotic cells on the examined slides. As seen in Figures 10A-10C, based on this method, we obtained strong imaging evidence that more than $95 \%$ of the tumor cells were apoptotic after irradiation. On the other hand, the apoptotic rate of the surrounding healthy cells was less than $2 \%$ (Figures 10D-10F) on all the examined slides $(P<0.0001)$. These observations strongly suggest the specific nature of our treatment and confirmed its efficacy in inducing selective apoptosis in human pancreatic adenocarcinoma.

The hallmark of cell lysis is represented by DNA degradation, which in the early stages is selective to the internucleosomal DNA linker regions. The DNA cleavage may yield double-stranded and single-stranded DNA breaks (nicks). Both types of breaks can be detected by labeling the free $3^{\prime}-\mathrm{OH}$ termini with modified nucleotides such as 

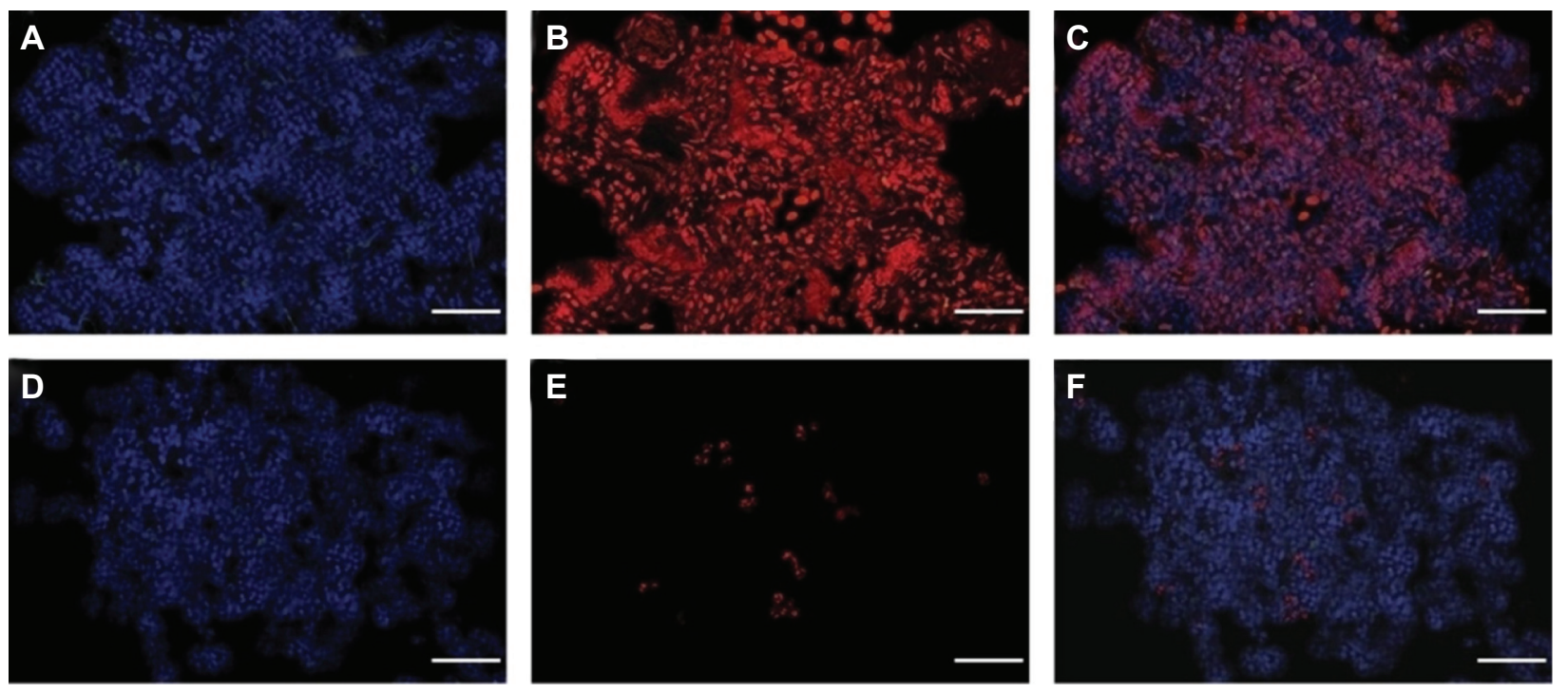

Figure 10 Postirradiation effects after intra-arterial administration of HSA-MWCNTs. TUNEL TMR apoptosis assay (red), DAPI nuclear staining (blue), and overlay. A-C) Pancreatic adenocarcinoma. D-G) Normal pancreatic tissue. Scale bar: $100 \mu \mathrm{m}$. Results are representative of three experiments.

Abbreviations: DAPI, 4',6-diamidino-2-phenylindole; HSA, human serum albumin; MWCNT, multiwalled carbon nanotubes; TUNEL, transferase dUTP nick end labeling.

fluorescein-dUTP in an enzymatic reaction. The terminal deoxynucleotidyl transferase (TdT) catalyzes the templateindependent polymerization of deoxyribonucleotides to the $3^{\prime}$-end of single- and double-stranded DNA. This method is recognized for its high sensitivity and specificity for apoptotic cell detection in tissue sections. ${ }^{40}$ This selective destruction of the tumor tissue has additionally confirmed the efficacy of the selective internalization of MWCNTs, with HSA cargo, inside the ductal pancreatic adenocarcinoma after intra-arterial perfusion.

According to the information provided by the remote temperature measurements, in the present study, the HSA-MWCNT-mediated heating was tumor-specific, and consequently, the risk of damaging collateral structures was insignificant. Therefore, a clinical development of such treatment would have great benefit.

If we dissect the molecular detail of the HSA-MWCNTmediated laser ablation mechanism, we obtain a selective necrosis of each malignant cell at a micrometric scale, with consequent global tumor involution. This is of decisive importance since all the current thermal ablation techniques in surgery rely on the use of invasive electrodes that generate high local temperature $\left(90^{\circ} \mathrm{C}\right)$, with nonselective carbonization of the tissue. Therefore, methods such as radiofrequency or ultrasound ablation are not used in pancreatic surgery (they have limited applications in liver and kidney tumor treatment). ${ }^{41}$ Due to the burning effects on the tissue, complications of these techniques in surgical practice, such as the extensive destruction of normal tissue with organ failure, residual abscesses, vascular injuries and peritoneal hemorrhage, neoplastic seeding, and intestinal perforation, are quite common. ${ }^{42}$

The spread of PC cells in the systemic circulation, with consequent seeding in other organs, a process called metastasis, is the cause of most PC-related deaths. Thus, the development of selective targeted therapies able to destroy these circulating cells could open a new era in the treatment of PC. Therefore, there is a dire need for innovations of such molecular "Trojan horses", able to produce safe single-cell necrosis, with minimal side effects.

In this experiment, all the existent situations met in surgical practice were replicated. We reasoned that, from a surgical point of view, the ultrasound identification of the tumor and its vascular supply, the intra-arterial administration of the functionalized MWCNTs, as well as the external laser irradiation, could all be safely achieved in patients by means of minimally invasive surgery, with major benefits for the patient (eg, laparoscopic approach or percutaneous approach under ultrasound/CT guidance).

\section{Conclusion}

We showed for the first time that HSA-MWCNTs are selectively internalized in human pancreatic adenocarcinoma cells through the binding of albumin carrier to the gp60 receptor. Moreover, to our best knowledge, this is the first demonstration of the therapeutic potential of intra-arterially delivered nanobioconjugates in living human tumors. This is of decisive importance, especially with regard to the initiation 
of this therapeutic method in clinical trials. The proposed ex-vivo platform could be further used for the development and testing of new nanobioconjugates with specificity for PC. Thus, starting from this model, other ex-vivo platforms (eg, human hepatocellular carcinoma, kidney tumors) can be built, with the purpose of testing new active nanobiomolecules against human cancers.

The above results assign human albumin as having a good potential for use as a selective delivery carrier for the development of CNT-based targeting agents in the treatment of PC. This original therapeutic strategy (intra-arterial administration of nanobiosystems in living human organs) presented in this paper will likely increase the knowledge of CNT-mediated photothermal therapy in cancer and will open new doors in oncological research. Nevertheless, further research is required for the careful assessment of unexpected toxicities and biological interactions of HSA-MWCNTs inside the living organism.

\section{Ethical considerations}

The authors state that they have obtained appropriate institutional review board approval (decision number 7699/17.05.2010) and have followed the principles outlined in the Declaration of Helsinki for all human experimental investigations. For research regarding surgically resected specimens, informed consent has been obtained from the participants involved, and the experiments were tailored so that the future outcome or further therapeutic strategy would not affect these patients.

\section{Acknowledgment/disclosure}

Financial support from the Romanian Ministry of Education and Research (NANOPAN 41-009, NANOHEP 42-115 and NANOCITOX 42-112) is gratefully acknowledged. The authors also thank the Romanian Society of Nanomedicine and Nitech Company, represented by Ms Florina Carpiuc, for providing technical support for electron microscopy analysis.

\section{References}

1. Jemal A, Siegel R, Xu J, Ward E. Cancer statistics. CA Cancer J Clin. 2010;60(5):277-300.

2. Ghaneh P, Costello E, Neoptolemos JP. Biology and management of pancreatic cancer. Gut. 2007;56(8):1134-1152.

3. Borja-Cacho D, Jensen EH, Saluja AK, Buchsbaum DJ, Vickers SM. Molecular targeted therapies for pancreatic cancer. Am J Surg. 2008; 196(3):430-441.

4. Kam NW, O'Connell M, Wisdom JA, Dai H. Carbon nanotubes as multifunctional biological transporters and near-infrared agents for selective cancer cell destruction. Proc Natl Acad Sci U S A. 2005; 102(33):11600-11605.
5. Alexis F, Rhee JW, Richie JP, Radovic-Moreno AF, Langer R, Farokhzad OC. New frontiers in nanotechnology for cancer treatment. Urol Oncol. 2008;26(1):74-85.

6. Wang X, Wang Y, Chen ZG, Shin DM. Advances of cancer therapy by nanotechnology. Cancer Res Treat. 2009;41(1):1-11.

7. Gannon CJ, Patra CR, Bhattacharya R, Mukherjee P, Curley SA Intracellular gold nanoparticles enhance non-invasive radiofrequency thermal destruction of human gastrointestinal cancer cells. J Nanobiotechnology. 2008;6:2.

8. Eck W, Craig G, Sigdel A, et al. PEGylated gold nanoparticles conjugated to monoclonal F19 antibodies as targeted labeling agents for human pancreatic carcinoma tissue. ACS Nano. 2008;2(11): 2263-2272.

9. Mahmood M, Karmakar A, Fejleh A, et al. Synergistic enhancement of cancer therapy using a combination of carbon nanotubes and anti-tumor drug. Nanomedicine (Lond). 2009;4(8):883-893.

10. Di Stefano G, Fiume L, Bolondi L, Lanza M, Pariali M, Chieco P. Enhanced uptake of lactosaminated human albumin by rat hepatocarcinomas: implications for an improved chemotherapy of primary liver tumors. Liver Int. 2005;25(4):854-860.

11. Sinn H, Schrenk HH, Friedrich EA, Schilling U, Maier-Borst W. Design of compounds having an enhanced tumour uptake, using serum albumin as a carrier. Part I. Int J Rad Appl Instrum B. 1990;17(8):819-827.

12. Schilling U, Friedrich EA, Sinn H, Schrenk HH, Clorius JH, Maier-Borst W. Design of compounds having enhanced tumour uptake, using serum albumin as a carrier - Part II. In vivo studies. Int J Rad Appl Instrum B. 1992;19(6):685-695.

13. Stehle G, Wunder A, Sinn H. Pharmacokinetics of methotrexatealbumin conjugates in tumor-bearing rats. Anticancer Drugs. 2002; 13(6):615-623.

14. Garber K. Stromal depletion goes on trial in pancreatic cancer. J Natl Cancer Inst. 2010;102(7):448-450.

15. Kim JW, Shashkov EV, Galanzha EI, Kotagiri N, Zharov VP. Photothermal antimicrobial nano-therapy and nanodiagnostics with self-assembling carbon nanotube clusters. Lasers Surg Med. 2007;39(7): 622-634.

16. Bharali DJ, Khalil M, Gurbuz M, Simone TM, Mousa SA. Nanoparticles and cancer therapy: a concise review with emphasis on dendrimers. Int J Nanomedicine. 2009;4:1-7.

17. Lapotko D, Lukianova E, Potapnev M, Aleinikova O, Oraevsky A. Method of laser activated nano-thermolysis for elimination of tumor cells. Cancer Lett. 2006;239(1):36-45.

18. Welsher K, Liu Z, Daranciang D, Dai H. Selective probing and imaging of cells with single walled carbon nanotubes as near-infrared fluorescent molecules. Nano Lett. 2008;8(2):586-590.

19. Bianco A, Kostarelos K, Partidos CD, Prato M. Biomedical applications of functionalized carbon nanotubes. Chemical Communications. 2005;6(5):571-577.

20. Ting G, Chang CH, Wang HE. Cancer nanotargeted radiopharmaceuticals for tumor imaging and therapy. Anticancer Res. 2009;29(10): 4107-4118.

21. Ferrari M. Cancer nanotechnology: opportunities and challenges. Nat Rev Cancer. 2005;5(3):161-171.

22. Sharkey FE, Fogh J. Considerations in the use of nude mice for cancer research. Cancer Metastasis Rev. 1984;13(4):341-360.

23. Stretch GL, Nation RL, Evans AM, Milne RW. Organ perfusion techniques in drug development. Drug Dev Res. 1999;21(46):292-301.

24. Tiruppathi C, Finnegan A, Malik AB. Isolation and characterization of a cell surface albumin-binding protein from vascular endothelial cells. Proc Natl Acad Sci US A. 1996;9(93):250-254.

25. Tirupathi C, Song W, Bergenfeldt M, Sass P, Malik AB. Gp60 activation mediates albumin transcytosis in endothelial cells by tyrosine kinasedependent pathway. J Biol Chem. 272(41):29568-29575.

26. Iancu C, Mocan L, Bele C, et al. Enhanced laser thermal ablation for the in vitro treatment of liver cancer by specific delivery of multiwalled carbon nanotubes functionalized with human serum albumin. Int $J$ Nanomedicine. 2011;6:129-141. 
27. McLaren AJ, Friend PJ. Trends in organ preservation. Transpl Int. 2003;10:701-708.

28. Shi Kam NW, Jessop TC, Wender PA, Dai H. Nanotube molecular transporters: internalization of carbon nanotube-protein conjugates into Mammalian cells. J Am Chem Soc. 2004;126(22): $6850-6851$

29. Kovtyukhova NI, Mallouk TE, Pan L, Dickey EC. Individual singlewalled nanotubes and hydrogels made by oxidative exfoliation of carbon nanotube ropes. J Am Chem Soc. 2003;125(32):9761-9769.

30. Socrates G. Infrared and Raman characteristic Group Frequencies. Tables and Charts. 3rd ed Chichester: John Wiley and Sons; 2001.

31. Maeda H, Ishida N, Kawauchi H, Tsujimura K. Reaction of fluoresceinisothiocyanate with proteins and amino acids. I. Covalent and noncovalent binding of fluorescein-isothiocyanate and fluorescein to proteins. J Biochem. 1969;65(5):777-783.

32. Kroll A, Pillukat MH, Hahn D, Schnekenburger J. Current in vitro methods in nanoparticle risk assessment: limitations and challenges. Eur J Pharm Biopharm. 2009;72(2):370-377.

33. Greim H, Andrae U, Forster U, Schwarz L. Application, limitations and research requirements of in vitro test systems in toxicology. Arch Toxicol Suppl. 1986;9:225-236.

34. Botos E, Klumperman J, Oorschot V. Caveolin-1 is transported to multi-vesicular bodies after albumin-induced endocytosis of caveolae in HepG2 cells. J Cell Mol Med. 2008;12(5A):1632-1639.
35. Masellis AM, SielaffTD, Bender GP. Successful treatment of metastatic pancreatic adenocarcinoma with combination chemotherapy regimens. Int J Clin Oncol. 2009;14(5):478-481.

36. Zharov VP, Galitovskaya EN, Jonson C, Kelly T. Synergistic enhancement of selective nanophotothermolysis with gold nanoclusters: potential for cancer therapy. Laser Surg Med. 2005;37(3):219-226.

37. Moon HK, Lee SH, Choi HC. In vivo near-infrared mediated tumor destruction by photothermal effect of carbon nanotubes. ACS Nano. 2009;3(11):3707-3713.

38. Jain PK, Huang X, El-Sayed IH, El-Sayed MA. Noble metals on the nanoscale: optical and photothermal properties and some applications in imaging, sensing, biology, and medicine. Acc Chem Res. 2008;41(12):1578-1586.

39. Dresselhaus MS, Dai H. Carbon nanotubes: continued innovation and challenges. MRS Bull Adv Carbon Nanotubes. 2004;29:237-243.

40. Martinez MM, Reif RD, Pappas D. Detection of apoptosis: a review of conventional and novel techniques. Anal Methods. 2010;2:996-1004.

41. Lau WY, Leung TW, Yu SC, Ho SK. Percutaneous local ablative therapy for hepatocellular carcinoma: a review and look into the future. Ann Surg. 2003;237(2):171-179.

42. Livraghi T, Solbiati L, Meloni MF. Gazelle GS, Halpern EF, Goldberg SN. Treatment of focal liver tumors with percutaneous radio-frequency ablation: complications encountered in a multicenter study. Radiology. 2003;226(2):441-451.
International Journal of Nanomedicine

\section{Publish your work in this journal}

The International Journal of Nanomedicine is an international, peerreviewed journal focusing on the application of nanotechnology in diagnostics, therapeutics, and drug delivery systems throughout the biomedical field. This journal is indexed on PubMed Central, MedLine, CAS, SciSearch ${ }^{\circledR}$, Current Contents ${ }^{\circledR} /$ Clinical Medicine,

\section{Dovepress}

Journal Citation Reports/Science Edition, EMBase, Scopus and the Elsevier Bibliographic databases. The manuscript management system is completely online and includes a very quick and fair peer-review system, which is all easy to use. Visit http://www.dovepress.com/ testimonials.php to read real quotes from published authors. 